\title{
TRENDS OF THE DAILY MAXIMUM TEMPERATURES IN RELATION WITH THE CLIMATIC CHANGE AND THE URBANIZATION IN THE ATHENS BASIN
}

\author{
M. TZANAKOU ${ }^{1}$ \\ D. DELIGIORGI ${ }^{2, *}$
}

\author{
${ }^{1}$ Hellenic National Meteorological Service \\ Helliniko, Greece \\ ${ }^{2}$ National and Kapodistrian University of Athens \\ Dept. of Physics, Physics of Atmospheric Environment Lab.
}

GR-15784, Athens, Greece
Received: 30/03/06

Accepted: 02/05/06 *to whom all correspondence should be addressed: e-mail: despo@phys.uoa.gr

\begin{abstract}
It is well known that the studies that associate the climatic changes with the greenhouse effect, as a sequence of uninterruptedly ongoing figures in the concentration mainly of carbon dioxide, have been focused on the trends of the mean temperature. On the other hand the variability and the trends of the extreme temperature values have not been considered sufficiently. We notice that the variability of the maximum and minimum temperature values and generally of the extreme weather has direct economic and societal implications.

The interest in this paper is focused on the study of the trends of the daily and the monthly maximum temperature during the warm months July and August for the time period from 1955 to 2000 in the wide Athens area and specifically measurements of the Nea Philadelphia and Helliniko meteorological stations. Nea Philadelphia represents an immiscibly urban area station, while Helliniko a coastal suburban area one. The specific sites were selected for the comparative study of the temperature maximum trends in a time period which covers the population growth in the area of Athens.

For the whole time period, the differences of the daily maximum temperature from the corresponding 10-days period mean maximum temperatures per month were calculated for each site. Then, the days with positive difference per month and per year as well as the trends of the time-series for each station were recorded along with the statistical significance of the regression slope's value using the Student t-test distribution.

Furthermore, in order to identify the "warmest decade" in the time-series, a study of the daily maximum temperature trend for the months July and August was performed for each decade followed by a test for the statistical significance of the slope coefficient.

It is known that the presumable differences of the temperature time-series depend on the influence of the urbanization, the modification of the natural suburban environment and / or on the stations' displacement. Based on these facts, we present more in this paper the conclusions of a comparative study of the results regarding each station analytically as well as the interpretation of the results concerning all the stations as an ensemble.
\end{abstract}

KEYWORDS: air temperature, long-term variability, time series analysis, maximum urban temperature

\section{INTRODUCTION}

Extreme climatic events have a high cost in terms of agriculture damage, forest-fires, as well as in human health and death loss. It is well known that the question of whether rising mean air temperatures is caused either by increasing emissions of greenhouse gases or by variability of climate has not been answered yet. Studies that associate the climatic changes with the greenhouse effect, as a sequence of uninterruptedly ongoing figures in the concentration mainly of carbon dioxide, have been focused on the trends of the mean 
temperature. On the other hand, the variability and the trends of the extreme temperature values have not been considered sufficiently.

Information related on trends in climatic variability and extremes are important for evaluating the magnitude and impacts of recent climatic changes. Furthermore, relatively limited research has dealt on how parameters of daily air temperature frequency distributions other than the mean have changed with time or how they interact with one another.

The topography of Greece and its location in the eastern Mediterranean imply strong influence from the local circulation. Greece shows a slight negative trend in air temperature over the 20th century [2] [5] [7]. An overall cooling trend was detected for the majority of Greek stations in winter for the period 1955-2001, whereas, summer shows an overall warming trend, however, neither are statistically significant [6] [1]. According to a more recent study winter temperatures in Greece present a cooling trend during the period 1957-1997 [3]. The 1970's has been the coldest decade of the 20th century in Greece [2].

\section{AREA, DATA AND METHODS}

The topography of the Athens basin is highly variable and its vicinity with the sea is the dominating factor on the climate. Several different morphological structures can be found in close proximity, and their diversity is reflected in the values of meteorological elements observed. The differences arise due to the relief of the terrain, various expositions of the slopes and land-use types.

In this paper the series of daily maximum air temperatures from 1955 to 2000 for two months (July and August) and for two stations Helliniko and Nea Philadelphia (Table 1 and Figure 1) were used to analyze the climatic changes.

The specific sites were selected for a comparative study of the maximum air temperature trends in a time period that covers the population growth in the area of Athens. Furthermore, five basic criteria determined the site selection: (a) the existence of two meteorological stations and the availability of continuous series of data over a long period of time, (b) the homogeneous data series over their entire length, (c) the easily updateable and likely to continue for the foreseeable future, (d) the relative proximity of the two stations and (e) the fact that Nea Philadelphia station is an urban station inland and Helliniko station is a coastal suburban station.

The climatic characteristics of the stations are as following:

Helliniko is a suburban station and during yearly study is mainly influenced from the prevailing Northeastern flows and the Saronic Gulf sea-breeze circulation. As a result to the sea-breeze circulation the temperature decreases during the warm period. During the etesian winds period, the strong Northeastern flows take the form of katabatic flows from Hymettos Mountain causing adiabatic heating in the lower troposphere, increasing the air temperature. These phenomena combined with the effects of urbanization, explain the temperature differences that are recorded regarding the stations of Nea Philadelphia and Helliniko.

The station of Nea Philadelphia is a representative urban station of Athens basin. The station is not affected significantly from the sea-breeze circulation, due to urbanization and the big distance from the shore. The effect of the urbanization in the daily variation of temperature is well known. The heat that is accumulated during the day is released during the night, resulting higher temperature values during the entire day, compared with the coastal and suburban ones.

Table 1. Geographic data for the selected stations.

\begin{tabular}{llcc}
\hline \multicolumn{1}{c}{ Station } & Latitude & Longitude & Altitude (m) \\
\hline Nea Philadelphia & $38^{0} 03^{\prime}$ & $23^{\circ} 40^{\prime}$ & 136.1 \\
\hline Helliniko & $37^{\circ} 54^{\prime}$ & $23^{\circ} 45^{\prime}$ & 10.0 \\
\hline
\end{tabular}

The months July and August were selected as the most representative with respect to the features of the thermal regime changes in surface atmosphere both on average for a year and at extreme annual variations. 


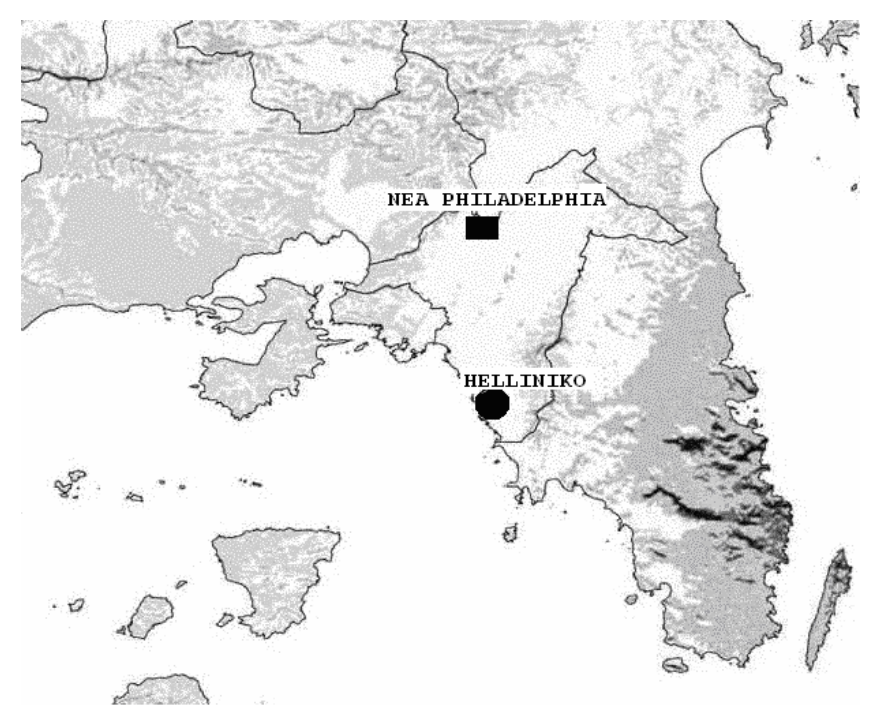

Figure 1. Map of Attica district and station locations

The normal maximum temperatures are calculated based on arithmetic mean of climate data, computed for all the period 1955-1997 and once per decade for the two months. These values are benchmarks to be used throughout the decade as a measure of central tendency. The normal data can be useful in placing ongoing weather conditions in historical context. Specially, the normal data offer an excellent tool for describing climate variability across space. This practice is used to take into account the slow variations in climate as well as to illustrate the changes introduced into the recorded data due to: the hourly alterations observed, the observational practices, the site or instruments used, or a gradual change in the character of the surrounding area, such as the growth of a city.

At the second stage, the normal conditions are calculated on 10-day (decameron) average for July and August for the whole period under study (Table 2). Averaging gives a good seasonal sampling from many days of data surrounding the target date and reduces aberrations for a single date.

Table 2. Mean daily maximum temperature per 10-days period (decameron) for the stations of Helliniko and Nea Philadelphia for the period 1955-1997.

\begin{tabular}{cccc}
\hline Month & Decameron & Helliniko $\left({ }^{\circ} \mathrm{C}\right)$ & Nea Philadelphia $\left({ }^{\circ} \mathrm{C}\right)$ \\
\hline \multirow{3}{*}{ July } & 1st & 30.7 & 33.1 \\
\cline { 2 - 4 } & 2nd & 32.1 & 33.8 \\
\cline { 2 - 4 } & 3rd & 32.1 & 33.8 \\
\hline \multirow{3}{*}{ August } & 1st & 32.3 & 33.9 \\
\cline { 2 - 4 } & 2nd & 32.0 & 33.5 \\
\cline { 2 - 4 } & 3rd & 30.8 & 32.4 \\
\hline
\end{tabular}

Regarding the variability of the mean decameron maximum air temperature, at each of the stations an increase can be observed from the first decameron of July to the first decameron of August and a decrease to the two next decameron, the rate of increase or decrease, however, were different at each station (Table 2).

For the whole time period, the differences of the daily maximum temperature from the corresponding 10-days period mean maximum temperatures per month (July and August) were calculated for each site. Then, the days with positive difference per month and per year as well as the trends of the time-series for each station were recorded along with the statistical significance of the regression slope's value using the Student t-test distribution.

Furthermore, in order to identify the "warmest decade" in the time-series, a study of the daily maximum temperature trend for the months July and August was performed for each decade from 1960 to 1999 followed by a test for the statistical significance of the slope coefficient. 


\section{DISCUSSION AND CONCLUSIONS}

The sum of the number of days with positive difference from the mean maximum temperature for all the period and for each decade and per station is shown in Table 3. From the values in Table 3 it is shown that for the station at Helliniko, July has greater number of days with positive difference, while August is the respective month for the station of Nea Philadelphia. Furthermore, the warmest decade is the 90's $(1990$ - 1999) for the both stations.

Looking at the data for the entire observation period, we observe a characteristic tendency of warming. It can be seen that the trends for different periods are different (Table 3 and Figure 2). The variability in trends indicate that there was not one uniform trend of either increasing or decreasing in the number of days, where the temperatures are higher than the means of 10-days period, over the 1955-2000 period for the Athens basin. The analysis revealed a positive, statistically significant trend in the number of days, where the temperatures are higher than the means of 10-days period, for all the period 1955-2000 at Helliniko station only in the July and at Nea Philadelphia in the two months (Table 3). For the decades periods, at Helliniko station there is positive, statistically significant trend for the two months in the third decade (1980-1989) and at Nea Philadelphia station only in August for the same decade (Table 3 and Figures 3 and 4 ).

Since the analysis for the entire 1955-2000 period of the record reflected the effects of urbanization on stations' climate, the fact that the two station have positive, statistically significant trend in the number of days, where the temperatures are higher than the means of 10-days period suggests that the urbanization effect on stations' climate occurred step by step during all the 1955-2000 period but more intense for the Helliniko station in the third decade.

The considerable difference between the temperature trends at the two stations is likely due to the station locations. While they are not far apart in distance, Nea Philadelphia has undergone significant changes in land use and population as the result of urbanization. Helliniko remain a relative small community.

Table 3. Number of the days with positive differences, values of the slope $b$ (in days/year) of the linear regression analysis for the period 1955-2000 and for the forth decades for the stations of Helliniko and Nea Philadelphia. Trends statistically significant at the $95 \%$ confidence level are given in bold type. The t critical value is 2.015 for a 46 year-long measurements series and 2.306 for a decade measurements series.

\begin{tabular}{|c|c|c|c|c|c|c|c|}
\hline \multirow[t]{2}{*}{ Station } & \multirow[t]{2}{*}{ Period } & \multicolumn{3}{|c|}{ July } & \multicolumn{3}{|c|}{ August } \\
\hline & & $\begin{array}{l}\text { number } \\
\text { of days }\end{array}$ & Slope b & $\mathrm{t}$ & $\begin{array}{l}\text { number } \\
\text { of days }\end{array}$ & Slope b & $\mathrm{t}$ \\
\hline \multicolumn{8}{|l|}{ Helliniko } \\
\hline & $1955-2000$ & 742 & 0.1322 & 2.105 & 721 & 0.0548 & 0.5886 \\
\hline & 1960-1969 & 157 & -0.6364 & 1.554 & 162 & -0.9455 & -0.86 \\
\hline & $1970-1979$ & 121 & 0.0303 & 0.0546 & 107 & -1.0485 & 1.7359 \\
\hline & 1980-1989 & 143 & 1.3152 & 3.017 & 121 & 1.1333 & 2.345 \\
\hline & 1990-1999 & 212 & 1.1394 & 1.666 & 207 & 0.7333 & 0.906 \\
\hline \multicolumn{8}{|c|}{ Nea Philadelphia } \\
\hline & $1955-2000$ & 652 & 0.1965 & 3.592 & 710 & 0.1638 & 2.5238 \\
\hline & $1960-1969$ & 111 & -0.6242 & 1.2738 & 140 & -0.8 & -1.2574 \\
\hline & $1970-1979$ & 125 & 0.6364 & 0.8913 & 135 & -0.0545 & -0.086 \\
\hline & $1980-1989$ & 158 & 0.1576 & 0.2542 & 174 & 1.3212 & 2.376 \\
\hline & 1990-1999 & 177 & 0.8182 & 1.7228 & 179 & 0.3455 & 0.4778 \\
\hline
\end{tabular}


The statistically important increasing trend of the slope coefficient that was found for the two months (for July 1.9 days/decade and for August 1.6 days/decade) at the station of Nea Philadelphia is characteristic of the effect of urbanization, however, as it is shown from the study of each decade separately, there is no evidence of a statistically important increasing trend, except during August in the 80's (1980 - 1989). For the study of the effect of climate change and urbanization, the need of a massive time series, is scientifically acceptable, in order the climate periodic waves to be included and discriminated from the local changes. For the station of Helliniko a statistically important increasing trend for the third decade (1980 1989 ) it is observed. This trend is attributed to the change of the position of the station in the greater area of the airport.

Furthermore, for the period of the 46 years we have calculated the total number of cases, which for July or August the days with positive difference from the mean maximum temperature were above 15 , or those cases that for more than the half days of the month the maximum daily temperature was above the maximum mean temperature (Table 4). We observe that only for the Nea Philadelphia station and for the month July less than half of the whole period (16 cases) have positive temperature difference above 15. In contrast, in August for both stations and in July for Helliniko we have noticed almost equally distributions.
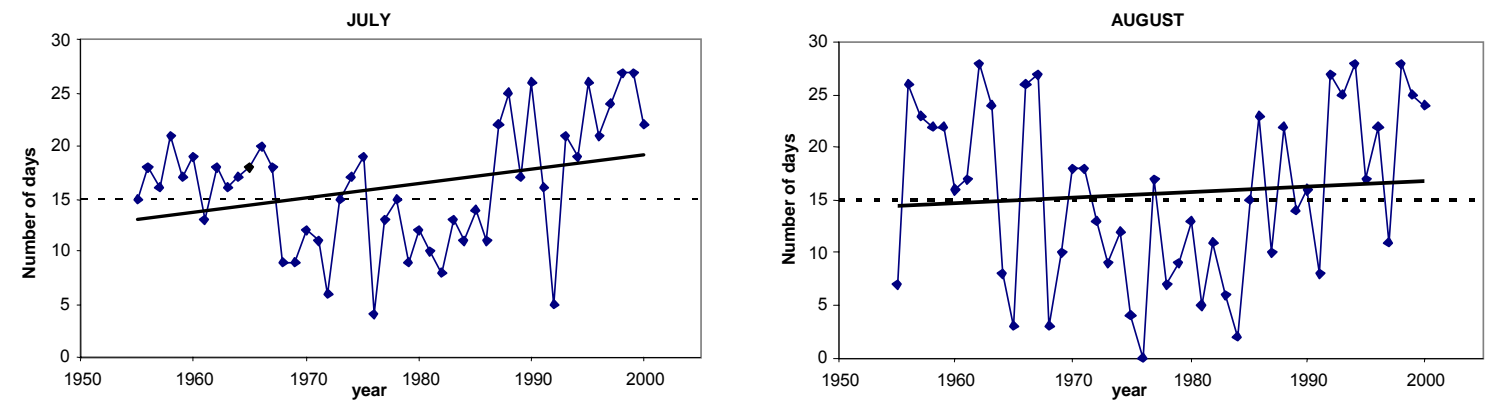

(a)
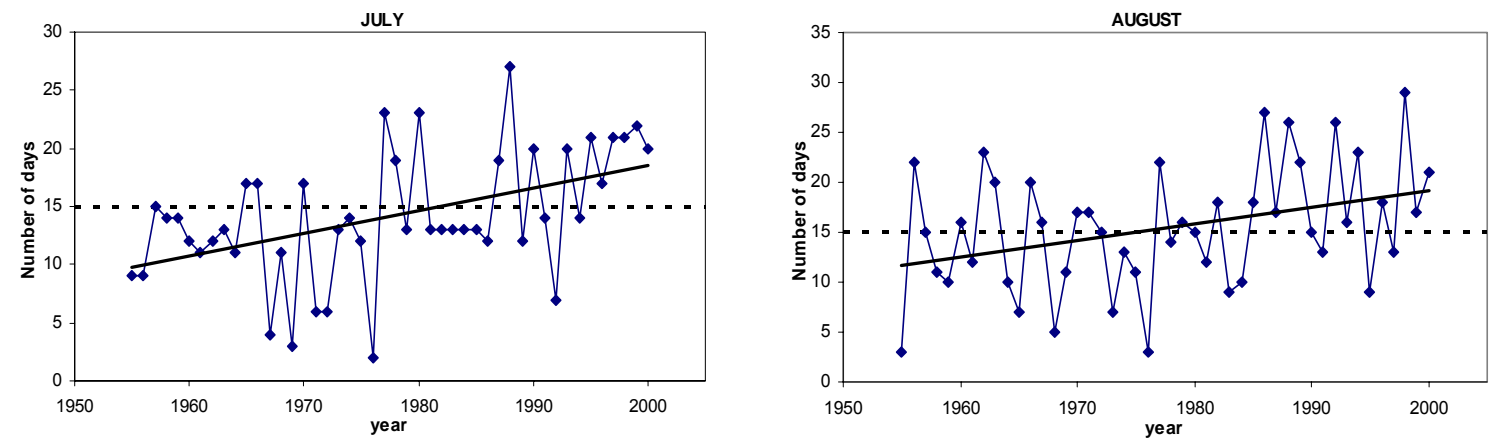

(b)

Figure 2. Time series ( $\square-$ ) of yearly number of the days with positive differences for July and August and their linear trends (- ${ }^{-}$) at (a) Helliniko and (b) Nea Philadelphia stations in the period 1955-2000. Dashed line represents the 15-day limit.

Table 4. Total number of cases for the 46 years period, which for July or August the days with positive difference from the mean maximum temperature were above 15.

\begin{tabular}{lll}
\hline Station & July & August \\
\hline Nea Philadelphia & 16 years & 23 years \\
\hline Helliniko & 26 years & 24 years \\
\hline
\end{tabular}

In Figure 2 we noticed that the number of years, where for both stations the days with positive difference from the mean maximum temperature were above 15 , occur in the last decade. On the other hand, in August at Helliniko station that occurs also for the first decade. 
1st Decade - July

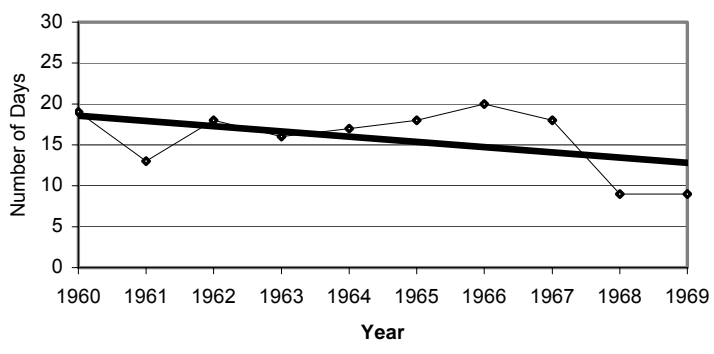

3rd Decade - July

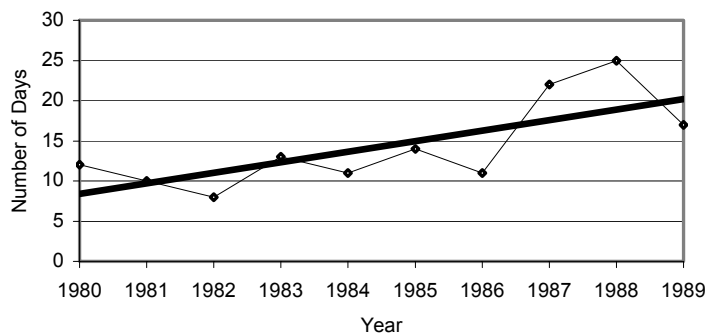

1st Decade - July

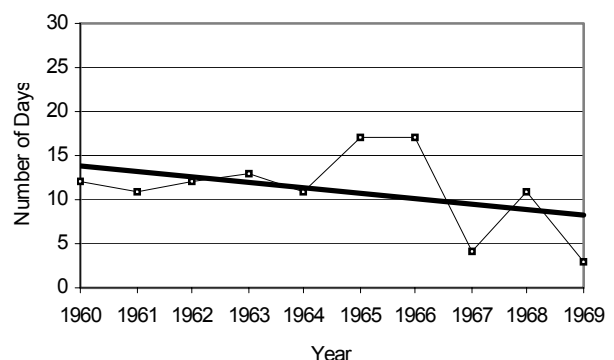

3rd Decade - July

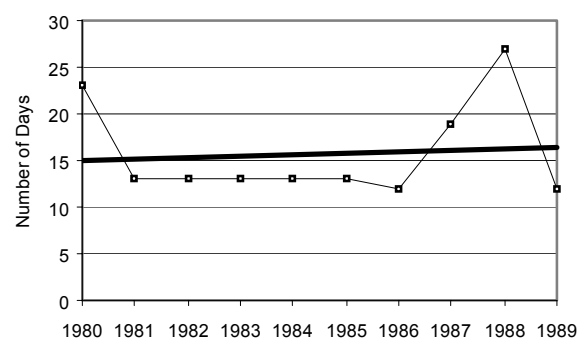

Year 2nd Decade - July

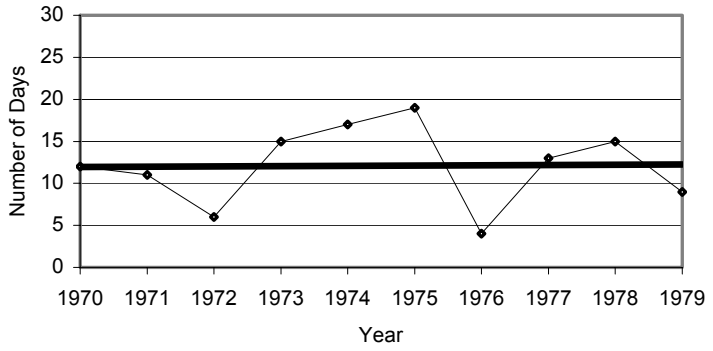

4th Decade - July

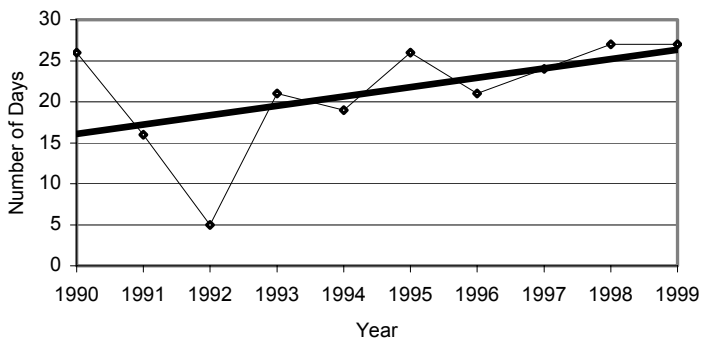

(a)

2nd Decade - July

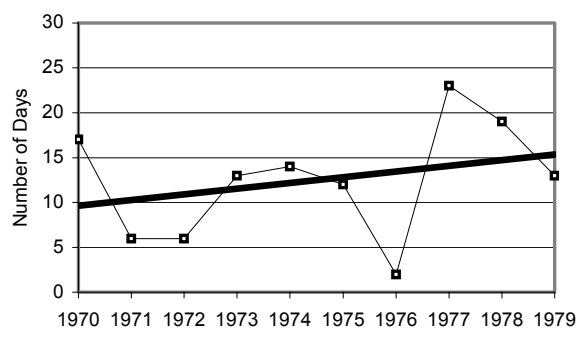

Year

4th Decade - July

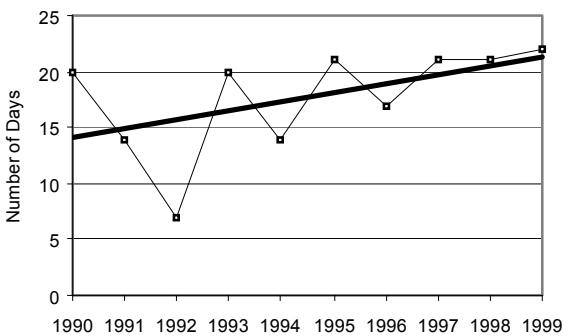

Year

(b)

Figure 3. Time series ( $\square-$ ) of yearly number of the days with positive differences per decade and their linear trends (- at (a) Helliniko and (b) Nea Philadelphia stations in the period 1960-1999 for July. 
1st Decade - August

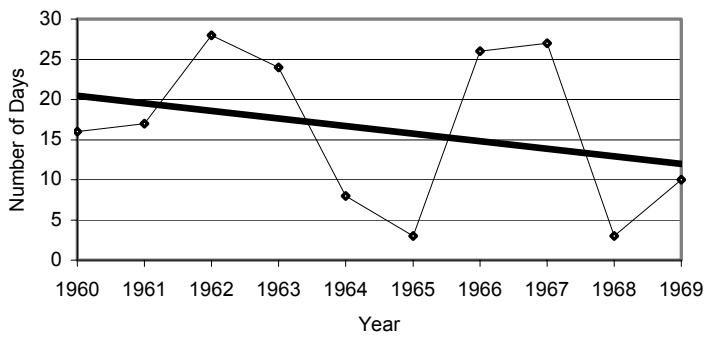

3rd Decade - August

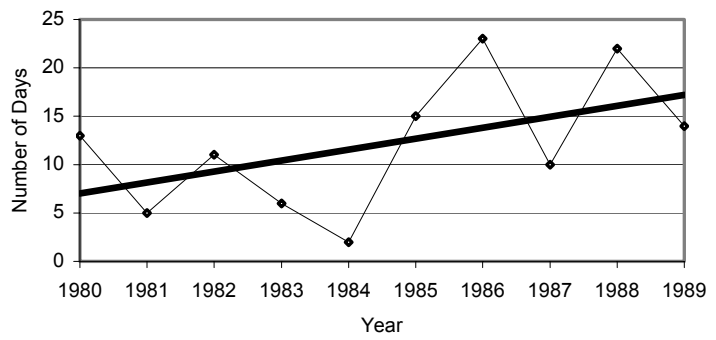

(a)

1st Decade - August

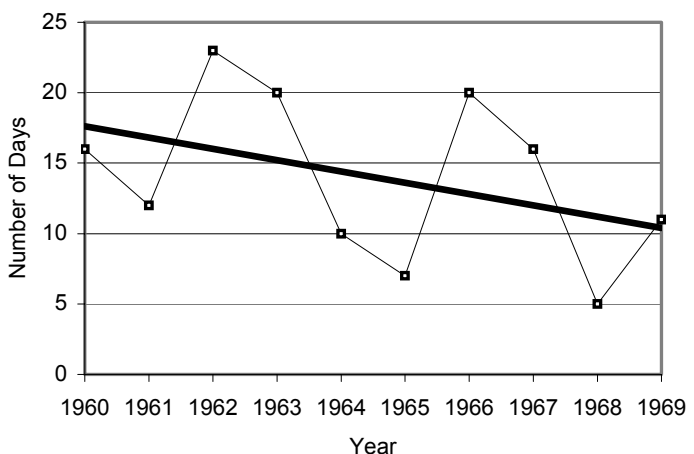

3rd Decade - August

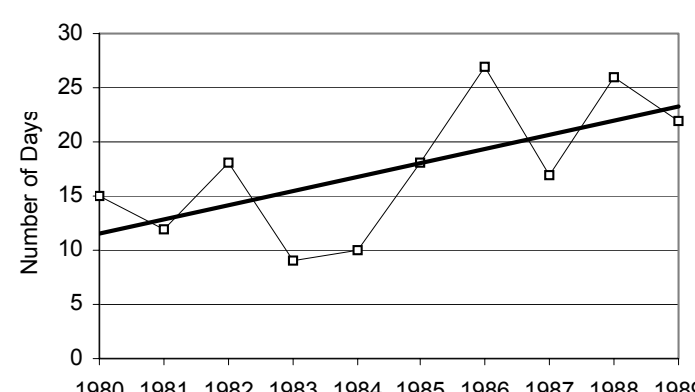

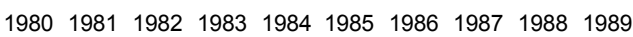
Year 2nd Decade - August

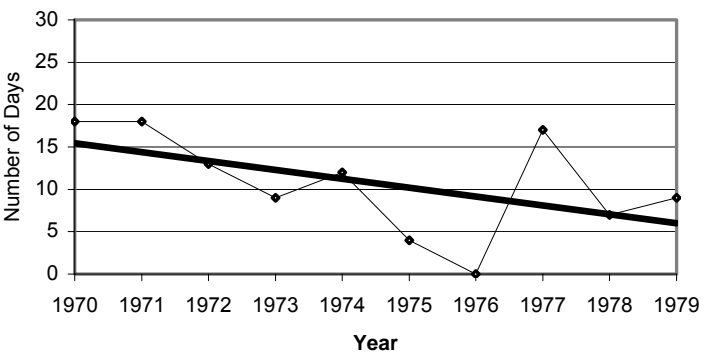

4th Decade - August

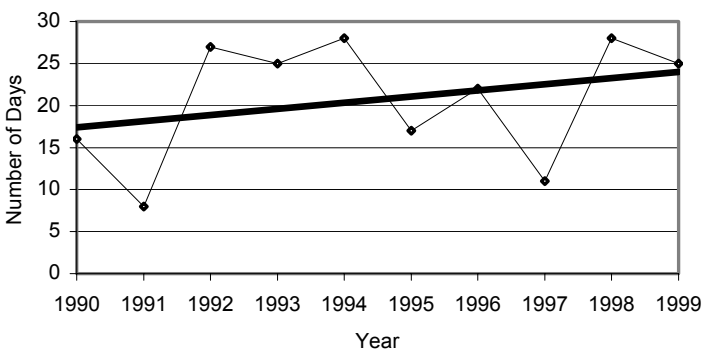

2nd Decade - August

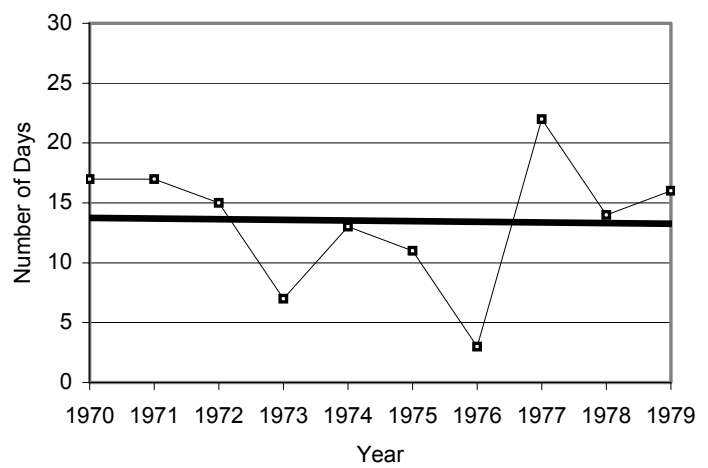

4th Decade - August

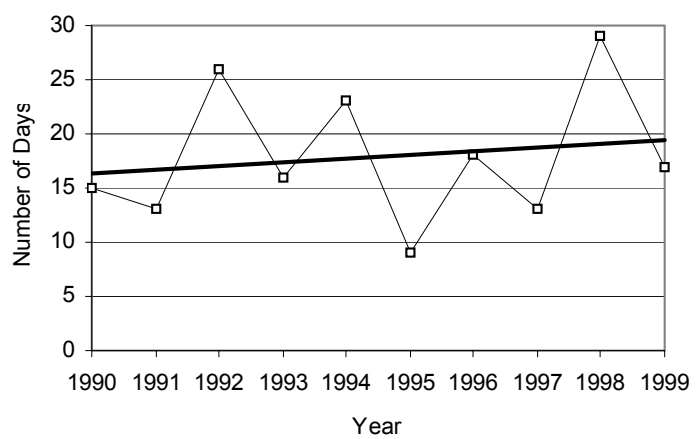

(b)

Figure 4. Time series ( $\square-$ ) of yearly number of the days with positive differences per decade and their linear trends (- at (a) Helliniko and (b) Nea Philadelphia stations in the period 1960-1999 for August. 
For a general conclusion it can be said that an increase of the number of days with higher daily temperature from the climatic mean value it is observed. This fact can be attributed to the variation of the suburban structure in the Athens basin, however a more detailed study of data for a century period, it would be a great tool in order to provide an answer to the vast issue of the topic climate change by reason of urbanization.

\section{ACKNOWLEDGMENTS}

The work described in this paper has been partially supported by the PYTHAGORAS II project of the Operational Programme for Education and Initial Vocational Training (EPEAEK II) under the 3rd European Community Support Framework for Greece. The authors would like to thank the Hellenic National Meteorological Service for the provision of the temperature data.

\section{REFERENCES}

1. Feidas H., Makrogiannis T. and Bora-Senta E. (2004) Trend analysis of air temperature time series in Greece and their relationship with circulation using surface and satellite data: 19552001, Theor. Appl. Climatol., 79(3-4), 185-208.

2. Giles B.D., Flocas A.A. (1984) Air temperature variations in Greece. Part 1. Persistence, trend, and fluctuations, Int. J. of Climatology, 4, 531-539.

3. Luterbacher J., Xoplaki E., Burgard R., Schmutz C. (1998) Connection between the large scale lower atmospheric circulation and the winter temperature variability over Greece: 19571997, Proc. 5th Greek Scientific Conference in Meteorology-Climatology-Atmospheric Physics. Athens, 28-30 September 1998, 81-88 pp.

4. Makrogiannis T., Bora-Senta E., Philandras T. (1998) Analysis of the air temperature time series in Thessaloniki, Application of the ARIMA(p,d,q) models, Proc. 4th Greek Scientific Conference in Meteorology-Climatology-Atmospheric Physics, Athens, 22-25 September 1998, 219-224.

5. Mitchell T. and Hulme M. (2000) A country-by-country analysis of past and future warming rates, Tyndall Centre Internal Report. No. 1 URL: http://www.tyndall.uea.ac.uk/main.html

6. Proedrou M., Theoharatos G., Cartalis C. (1997) Variations and trends in annual and seasonal air temperature in Greece determined from ground and satellite measurements, Theor. Appl. Climatol., 57, 65-78.

7. Retalis D., Hatzioannou L., Pasiardis S., Nikolakis D., Asimakopoulos D.N., Lourantos N. (1998) Study of the Temperature Time Series in SE Greece and Cyprus, Proc. 4th Greek Scientific Conference in Meteorology-Climatology-Atmospheric Physics, Athens, 22-25 September 1998, 271-278. 